\title{
Participação Comunitária e Gestão Participativa em uma comunidade de Badajoz, Extremadura, Espanha
}

Case Report

\section{Community participation and participative management in a community of Badajoz, Extremadura, Spain}

\author{
Ana Carolina Diniz Oliveira ${ }^{1}$ \\ Ignacio Maynar Mariño ${ }^{2}$ \\ Maria Dolores Fernandez ${ }^{3}$ \\ Carmen Mata Benito ${ }^{4}$ \\ Jesús Cobaleda Gallardo ${ }^{4}$
}

\section{Resumo}

A proposta desenvolvida a partir dos profissionais técnicos do Centro de Saúde El Progresso, consiste em um início de um processo de intervenção e participação da comunidade para enfrentar os problemas e contribuir com a melhoria da qualidade de vida da população da área de abrangência, contando com serviços, recursos existentes e o apoio das instituições. Com estas reflexões se promoveu o Processo Comunitário da Margem Direita do Rio Guadiana descreveremos ao longo deste relato. A administração sanitária assume a formação da assistente social da equipe em torno das experiências comunitárias assessoradas pelo consultor externo contratado pelo governo, Dr Marco Marchioni, que contribuiu com a formação necessária para o desenvolvimento do processo comunitário. Para que esta coordenação evolua para uma intervenção conjunta, é necessária a realização de um Diagnóstico Comunitário que possibilite uma visão compartida, global e integral da comunidade. Esta primeira etapa do Processo Comunitário desenvolveu o Diagnóstico com todas as pessoas envolvidas e divulgou os resultados a toda a comunidade. Seguindo o esquema da análise DAFO, se pode dizer que a Margem Direita do Guadiana tem umas debilidades e umas fortalezas (análise interna) que se aproximam uma série de ameaças e de oportunidades (análise externa). Para conseguir participação comunitária e gestão participativa efetiva há que ter persistência e aproveitar as oportunidades. O tecido associativo da Margem direita do Rio Guadiana e o Diagnóstico da área servem para unir as pessoas em um objetivo comum e diminuir a dicotomização existente, fazendo com que as mudanças sejam positivas e que as ameaças se transformem em oportunidades.

Palavras-chave: Participação Comunitária; Gestão Participativa; Medicina de Família e Comunidade; Margem Direita do Rio Guadiana; Marco Marchioni; Processo Comunitário.
Key Words: Community Involvement and Participatory Management; Family Medical Phisycian; Right Margin of Guadiana River; Marco Marchioni; Comunity Process.

\footnotetext{
${ }^{1}$ Médica de Família e Comunidade da Prefeitura Municipal de Belo Horizonte- MG - Brasil.

${ }^{2}$ Médico e Doutor em Medicina de Família e comunidade do Centro de Saúde El Progresso- Equipe Comunitária da Margem Direita do Rio Guadiana (PCMDG)- Badajoz- Extremadura-Espanha.

${ }^{3}$ Enfermeira de Família e Comunidade do Centro de Saúde El Progresso- Equipe Comunitária da Margem Direita do Rio Guadiana (PCMDG)Badajoz- Extremadura-Espanha.

${ }^{4}$ Equipe Comunitária da Margem Direita do Rio Guadiana (PCMDG)- Badajoz- Extremadura- Espanha.
} 


\begin{abstract}
The proposal developed from the professional technicians from the Center for Health Progress, consists of a beginning of a process of intervention and participation of the community to address problems and contribute to improving the quality of life of people in the area of coverage, with services, resources and support of existing institutions. With these thoughts are promoted Procedure Committee of the right margin of the Guadiana river describe throughout this article. The administration takes the training of health social worker team's experiences around the community advised by March Marchioni, who helped with the training necessary for the development of the Community procedure. For this coordination to evolve a joint Intervention, it is necessary to carry out a Community Diagnosis enabling a shared vision, comprehensive and integrated community. This first stage of the process developed the Community Diagnosis with everyone involved and reported the results to the entire community. Following the pattern of analysis Dafoe, we can say that the right margin of the Guadiana river has some strengths and some weaknesses (internal analysis) approaching a series of threats and opportunities (external review). To achieve community participation and effective participatory management should be taken persistence and seize the opportunities. The fabric of voluntary right margin of Guadiana River Diagnóstico of area and serve to unite people in a common goal and to reduce existing dichotomization, so that the changes are positive and that threats become opportunities.
\end{abstract}

\section{Introdução}

Nos setores públicos básicos (sociais, educativos e sanitários) é uma realidade a escassez de recursos, tanto humanos como materiais. Dificilmente tem-se fartura, a não ser quando, os profissionais sentam-se e começam a enumerar os próprios recursos que coexistem em uma comunidade, percebendo assim uma grande quantidade de organizações, associações, serviços públicos, privados ou sem fins lucrativos, escolas, pessoas, voluntariados, ONGS, moradores, grupos de auto-ajuda, comércio, bares, praças, áreas de convivência, clubes, shoppings que fazem parte da comunidade.
O problema é a falta de coordenação existente entre eles, falta de comunicação, parcerias e contatos, muitas vezes, cada um fica trabalhando isolado em projetos e iniciativas particulares, sem se conectarem. Muitos têm uma série desarticulada de projetos setoriais, que seriam comuns, mas como não há interlocução dos atores, estes, não se confluem em um processo de melhora geral das condições de vida da comunidade ${ }^{1}$.

Mesmo diante de administrações diferentes, há uma tendência setorial com o instrumento das subvenções, tanto no estado central ou nas autonomias e prefeituras, o que se proporciona proliferar os projetos parciais, particulares, setoriais e com prazos, ao invés de serem processos globais, gerais e comunitários e permanentes. Muitas vezes, as administrações funcionam historicamente de maneira descoordenada em seu âmbito de atuação independente das outras e sem uma visão de conjunto da comunidade, cada uma com seu próprio diagnóstico e sua programação própria. Isto gera uma dificuldade de coordenação entre elas e também entre os profissionais das mesmas, assim como a impossibilidade de utilizar uma linguagem comum, que seria lógico, já que teoricamente as comunidades muitas vezes compartem de objetivos semelhantes.

Não há como esquecer a falta de formação curricular específica dos profissionais nos campos de atuação em que se espera sua intervenção para por em prática as leis e práticas sociais alternativas. Por exemplo, os profissionais da saúde não sabem atuar na promoção de saúde, os da educação, não são formados nem se proporcionam os meios para conseguir o desenvolvimento integral do escolar e os assistentes sociais não lhes ensinam a dinamizar a participação ativa da população para a articulação de uma rede social associativa.

Por outro lado está a população e seu grau de participação na vida pública: há excessiva delegação passiva dos agentes administrativos e técnicos para a solução dos problemas coletivos. O público e o coletivo aparecem como entidades alheias a todos, que só atuam quando os problemas coletivos os afetam negativa e diretamente ${ }^{2}$.

Tudo isto leva a valorizar o estado como assistencia- 
lista, não de bem estar, atuando sobre as consequências dos problemas e não sobre as causas, não se trabalha assim na prevenção dos mesmos. As administrações, os serviços e os profissionais, parecem estar para resolver os problemas dos clientes que perpetuam o que lhes é ensinado sentindose no direito de exigir, sem fazer a sua parte implicando-se como co-responsáveis.

Os resultados disto nos importantes setores da vida pública levam a um gasto sanitário cada vez mais elevado em farmácia e grandes recursos destinados ao diagnóstico e tratamento das doenças, mas com uma inversão infinitamente menor no campo da promoção de saúde e prevenção da doença.

Por outro lado, um fracasso escolar ressalta problemática complexa das famílias, seus recursos comunitários e os serviços sociais não conseguem dar uma melhor resposta as características presentes aos indivíduos em suas famílias e inseridos em uma comunidade.

Deste olhar parece desprender-se facilmente a necessidade de trabalhar de outra forma.

A realidade tem demonstrado que o esforço dos três protagonistas da comunidade (cidadania, administrações e recursos técnicos) unidos em prol de desenvolver um conjunto de intervenções que permitem a organização da mesma, através da coordenação das administrações, dos serviços, recursos, verbas (subvenções) e da participação ativa da população buscando entre todos este objetivo comum da melhoria na qualidade de vida.

Trabalhar em um processo de organização e desenvolvimento comunitário que se pretende obter metas à curto prazo; se trata de processos com início, mas sem fim ${ }^{1}$. Entendemos que é possível trabalhar nesta direção para iniciar um processo comunitário e assim buscar uma abordagem mais racional e satisfatória dos problemas tendo em conta as causas dos mesmos e por tanto as soluções destes devem ser multifatoriais ${ }^{3}$.

É muito importante ter em conta que não há um "gen” da participação entre os cidadãos e os grupos, sendo assim, estes aprendem a participar de um processo que requer instrumentos e canais que a tornam possível, participando e levando em conta a base da possibilidade de tomada de decisões e capacidade de influência. Neste processo de incorporação, as pessoas e os grupos adquirem autonomia e capacidade para atuar e melhorar sua situação.

Infelizmente a participação comunitária é um processo que se dá de forma espontânea e que habitualmente precisa de um impulso externo. O impulso pode ocorrer desde um centro de saúde e os profissionais sanitários, que devem contar desde o princípio com o apoio dos gestores dos serviços, as instituições, dos profissionais e a população atuando como um dinamizador muito importante e contribuindo com a credibilidade e o êxito da iniciativa ${ }^{4}$.

A proposta desenvolvida a partir dos profissionais técnicos do Centro de Saúde El Progresso consiste em um início de um processo de intervenção e participação da comunidade para enfrentar os problemas e contribuir com a melhora da qualidade de vida da população da zona (território), contando com o apoio dos recursos já existentes e a implicação das instituições e gestào do serviço.

O objetivo comum é a melhora da qualidade de vida e o bem estar da população valorizados de maneira integral e não só dos temas relacionados com a saúde e que esta seja a parte ativa das respostas sociais e não destinada passiva de ajudas.

Com estas reflexões se promoveu-se o Processo Comunitário da Margem Direita do Rio Guadiana (PCMDG) que vamos descrever ao longo deste artigo como experiência exitosa real e que conta com o apoio das administrações implicadas em desenvolver um papel fundamental para garantir este objetivo comum.

\section{O Território}

Com a "Margem Direita do Guadiana" fazemos referência aos bairros de Badajoz situados na margem direita do rio que corta a cidade. São onze bairros (São Fernando, Urbanização Guadiana, Santa Engracia, Nova Luneta, Gurugú, El Progresso - Campo Maior, Canhada Moreras, Jardins do Guadiana, Urbanização Rota da Expo, Urbanização Universitária e Urbanização Río Caia). Todos juntos somam quase 27.500 habitantes, $19,6 \%$ do total da 
população desta cidade, a mais povoada de Extremadura ${ }^{5}$.

É uma zona extensa onde podem encontrar todos os estratos sociais, dando notáveis contrastes entre os bairros com importante problemática social e recentes núcleos residenciais de alto nível econômico; encontramos também bairros de classe média, o polígono industrial, O Campo Universitário e o Hospital Regional Infanta Cristina.

A tradição associativa na zona é muito significativa (aqui se constituiu, por exemplo, a primeira Associação de Vizinhos de Badajoz), assim como a participação dos cidadãos.

\section{A Iniciativa}

A iniciativa comunitária que descrevemos brevemente surge desde o âmbito sanitário. Estes mesmos técnicos, antes eram profissionais do Centro de Saúde de São Fernando, que ao longo de vários anos de trabalho com a população e intervenções pontuais e isoladas, não conseguiam transformar a realidade e compreenderam que é preciso fazer confluir os esforços multisetoriais e articular os recursos com que conta a comunidade de uma maneira profissional, tendo o apoio das Administrações públicas mais importantes: sanitária, educativa e social, e contando com a população para que participe de forma ativa na análise e abordagem dos problemas comuns.

A Lei Geral de Saúde de 1986 contempla um modelo de Atenção Primária de Saúde baseado em uma concepção eminentemente preventiva e de Promoção da Saúde, que priorize o trabalho sobre o controle das causas dos problemas ${ }^{6}$. Entretanto, o desenvolvimento destas funções não foi para frente por ausência de uma vontade política clara e por falta de formação curricular entre os profissionais e a própria administração sanitária sobre como implantar as mesmas. Isto gera um sistema sanitário cada vez mais assistencialista e que só trabalha sobre as consequências dos problemas necessitando cada vez mais desenvolvimento tecnológico e um estilo de medicina defensiva, com enfoque muito biomédico. Tendo como consequência um enorme aumento da demanda sanitária assistencial com aumento incontrolável do gasto sanitário e orientado ao consumo dos recursos para o tratamento das doenças já instauradas e não a prevenção através da modificação dos estilos de vida. Ademais não se consegue uma melhora das condições de vida da população porque a origem dos problemas de saúde é multicausal e tem implicações psicológicas, sociais, econômicas e culturais que o sistema sanitário não aborda ${ }^{7}$.

Neste contexto estes profissionais sanitários organizados na "Área de Saúde Comunitária" no citado Centro de Saúde, tem a oportunidade de receber formação e capacitação sobre intervenção comunitária com o consultor do governo, Dr Marco Marchioni (Assistente Social, Sociólogo e Investigador Social) e aprendem não somente o que fazer senão também como se fazer de forma a coordenar os recursos técnicos de todos os serviços, tanto públicos como privados; implicando as administrações de todos esses serviços e assim conseguir uma participação ativa dos cidadãos. Busca-se fazer uma análise dos problemas setoriais e comuns, para ser capazes no futuro de trabalhar as necessidades de saúde, educativas e sociais, desde uma perspectiva não só assistencial, senão também preventiva e promocional, que modifique as demandas dos cidadãos e consiga uma melhoria da qualidade de vida em termos sustentáveis.

\section{O Inicio}

No ano de 2002, diante de uma demanda pontual de educação para a saúde do Colégio São José, os profissionais da área de saúde comunitária do Centro de Saúde, junto aos técnicos de serviços da comunidade do centro educativo, reorientam a intervenção formulando uma proposta de coordenação e colaboração dos recursos técnicos da zona e assim estudar em equipe como superar estas intervenções puntuais que não conseguem mudar atitudes, cria-se associações e introduz mudanças permanentes na realidade para melhorá-la. Assim, em outubro de 2002, se forma o Grupo Promotor para a coordenação dos recursos técnicos da Margem Direita do Guadiana (MDG), com dez técnicos de recursos da zona, e estes começam a reunirse periódicamente compartindo a idéia de que o fomento de um processo comunitário lhes aproximaria do objetivo 
comum compartido por todos diante de seus diferentes âmbitos de atuação (saúde, educação, assistência sociais, etc), melhorando a qualidade de vida da margem direita.

O grupo promotor se planeja como prioritário, junto à formação em metodologia comunitária, irá se apresentar nas distintas instituições das quais dependem os técnicos sobre a essência do processo comunitário e o papel de cada um dos protagonistas de toda a comunidade (técnicos, cidadania e administrações) já que sem apoio das instituições esta iniciativa se converterá em uma nova declaração de boas intenções e uma forma voluntária de trabalho.

Já neste momento inicial é patente o aumento da complexidade organizativa do grupo (convidar a melhorar os recursos, convocar reuniões, motivar a participação, cultivar relações, atas) e se faz necessária a figura de um profissional que se encarregue do trabalho inespecífico que leva ao desenvolvimento do processo.

A gerência da Atenção Primária da área de saúde de Badajoz, conhecedora do projeto que se está gerenciando, apóia desde o começo o processo de intervenção comunitária, assumindo suas principais pautas metodológicas e apontando como primeira contribuição ao processo, uma trabalhadora social para a equipe comunitária (novembro de 2003).

A existência de uma equipe comunitária, mesmo que pequena inicialmente, resulta determinante ao avanço da experiência.

Também o processo comunitário e seus protagonistas (técnicos, cidadãos e administrações e instituições) contaram desde o princípio com o trabalho metodológico inestimável, formativo e de assessoria do Dr. Marco Marchioni, contratado como consultor externo pela gerência de saúde de Badajoz.

\section{Desenvolvimento do Processo Comunitário (2004-} 2006)

A administração sanitária assume a formação da assistente social da equipe em torno das experiências comunitárias assessoradas por Marco Marchioni, que fez um trabalho anterior em Telde (Grande Canária) e fundou um instituto para fomentar a capacitação dos técnicos necessária para contribuir com o avanço efetivo do processo comunitário.

\subsection{Os RecursosTécnicos}

A Equipe comunitária trabalha nesta primeira etapa fazendo convite extensivo aos técnicos que trabalham na zona ou que atendem as demandas sociais da população para participar no processo comunitário, sempre de forma profissional, dentro do horário laboral, e com a implicação das equipes profisisonais, não como iniciativa isolada de alguns técnicos. A primeira reunião com uma presença maciça, coincide com a primeira visita do Dr. Marco Marchioni a Margem Direita em novembro de 2004, e nesta, se planeja a criação de um espaço permanente de encontro e intercâmbio entre os recursos constituindo o que chamamos de Comitê Técnico Assessor, formado na atualidade, por quarenta recursos de distintos setores. A sequência foi de uma a duas reuniões mensais. Entre as principais atividades nesta etapa, destaca-se o conhecimento mútuo como elemento necessário para a coordenação, a informação obtida deste conhecimento constitui a base da ficha de recursos. Também como atividade prioritária do grupo de coordenação técnica aparece a formação em metodologia de intervenção comunitária que se mantêm como atividade permanente até os dias atuais.

Hoje é um feito a consolidação do espaço de relação e coordenação que supõe o Comitê Técnico. A colaboração continuada dos recursos sanitários, serviços sociais e educativos proporcionaram ao redor destes os demais recursos mais específicos e ou mais finalistas que também encontraram. Este espaço é valorizado como um dos frutos mais valiosos do processo comunitário por todos os envolvidos e fomenta a aparição de colaboradores concretos.

O feito de que o conjunto de recursos técnicos tenham uma ampla e permanente informação metodológica permitiu estabelecer relações de colaboração e de intercâmbio mútuo. Tudo isto representa um elemento fundamental com vistas a qualquer intenção de promoção da participação 
da cidadania. E ao mesmo tempo, representa também a base de futuras relações técnicas entre diferentes recursos na hora de melhorar suas atuações, realizar intervenções mais globais e atender assim de maneira mais adequada as diferentes realidades sociais da zona.

\subsection{As Instituições}

Durante a primeira etapa se foi estabelecendo relações com distintas instituições com o propósito de lhes informar do processo, suas linhas metodológicas fundamentais e as atividades iniciadas e previstas, fomentando o apoio institucional a esta iniciativa.

Com o apoio da gerencia do distrito de saúde de Badajoz, como instituição promotora, e o "Documento Zero", como carta de apresentação, se mantêm as primeiras reuniões com a Direção Provincial de Educação, a Secretaria estadual de Bem Estar social, a Secretaria de Serviços Sociais, a Secretaria de Juventude e Infância e Saúde, e Cáritas. Estas primeiras reuniões fizeram possível ademais da informação, a presença de seus recursos no Comitê Técnico.

Um dos feitos destacados constitui a Comissão Institucional que se reúne pela primeira vez em junho de 2006 e novamente em dezembro deste ano convocada pela gerencia de saúde. Esta Comissão tem por finalidade constituir um marco de relação e colaboração entre as diferentes instituições, tanto públicas como privadas, que de alguma maneira estão colaborando no Processo comunitário.

A gerência do distrito de Badajoz assistiu as reuniões citadas junto a Direção Geral de Atenção Sócio-Sanitária (Serviço Extremenho de Saúde), o Serviço de Coordenação Sanitária (Secretaria de saúde), o Serviço Territorial de Badajoz da Secretaria de Bem Estar Social, o Serviço Extremenho Público de Emprego (Secretaria de Economia e trabalho). O Instituto Municipal de Serviços Sociais (Prefeitura de Badajoz) e a Agência de Moradias e de Urbanismo (Presidência da Junta de Extremadura) e Caritas Diocesana de Badajoz.

Facilita-se assim a adequada informação sobre o trabalho que se vem realizando os programas que irão desenvolvendo para que as diferentes instituições, cada uma no âmbito próprio de funcionamento e desde a mais ampla autonomia, possam integrar suas aportações e coordenar seus esforços. Esta implicação das instituições constitui sem dúvida um importante apoio da participação da cidadania em um marco de pluralismo e colaboração interinstitucional.

Continua nesta etapa o trabalho de informação sobre as linhas metodológicas do Processo Comunitário a outras instituições como Cruz vermelha (cujos técnicos participam do Comitê Técnico Assessor) ou a Diputação Providencial de Badajoz, que colabora com a edição de alguns documentos (guia de recursos, monografia comunitária).

Fruto da primeira reunião da Comissão Institucional se produz outro feito a se destacar nesta etapa: a ampliação da equipe comunitária com a liberação parcial dos novos profissionais: um assistente social da secretaria de Bem Estar Social (Badajoz) liberado de suas funções profissionais dois dias da semana para dedica ao processo comunitário e uma Educadora dos Serviços Sociais de base na Margem Direita do rio Guadiana (Instituto Municipal dos serviços sociais), liberada três horas semanais para trabalhar na Equipe Comunitária. A incorporação efetiva destes profissionais se produz em setembro de 2006 e com ela a necessidade de reajuste na organização da Equipe Comunitária e de formação dos novos membros do mesmo. A Assistente Social liberada pela Gerência do Distrito de Saúde de Badajoz em novembro de 2003 mantêm a dedicação exclusiva a Equipe Comunitária.

\subsection{A cidadania}

Desde o início do Processo Comunitário, se informou e implicou de forma paulatina a todo o tecido associativo existente na zona através de reuniões periódicas, de folhas informativas e de contatos individuais. A primeira reunião se celebrou em novembro de 2004 com as Associações de Vizinhos e os Centros de Promoção da Mulher; por entender que representam a um amplo número de cidadãos e dada a impossibilidade material neste momento de contactá-los com todo o tecido associativo para convidálos a esta primeira reunião, com a assistência do assessor 
do processo comunitário. O propósito era transmitir o sentido que tem na atualidade iniciar processos comunitários, e a nova forma de trabalho que os técnicos planejavam, partindo da coordenação dos recursos e o conhecimento compartido da realidade.

Depois deste primeiro contato, o trabalho da Equipe Comunitária centrou em ir contactando-se com as distintas associações para fazer chegar a todos a informação; o bom acolhimento da iniciativa comunitária e se traduz numa numerosa assistência (30 associações e mais de 70 pessoas) no "Primeiro Encontro de Associações e Cidadãos da Margem Direita do Guadiana” em março de 2005; se informou do trabalho dos técnicos e se convidou a todos para participar deste processo, começando esta participação por sentarse com a Equipe Comunitária para expressar quem são, que atividades realizam, quais são suas inquietudes, etc., de maneira que com esta informação os técnicos pudessem em um futuro construir diferentes Guias de Recursos da Margem Direita do Guadiana.

Em julho e novembro de 2005 se celebram novos encontros de associações e cidadãos e se pode falar da existência de um espaço de encontro do conjunto do movimento associativo da zona que reúne a todo tipo de associações assim como de pessoas que querem participar a título individual. Começa a surgir a idéia de que esta organização social vá definindo paulatinamente e sem pressa sua forma organizativa e funcional, e em outubro de 2005 , começa uma comissão começa a estudar a possibilidade de dar vida a uma associação de segundo nível que inclui tanto a representação de todas e cada uma das associações existentes, como pessoas que queiram participar a título particular, como simples cidadãos e cidadãs da região.

Também em novembro de 2005, se celebrou o primeiro encontro comunitário da Margem Direita do Guadiana. É a primeira vez que cidadãos, técnicos e instituições se encontram no marco do Processo Comunitário e têm a oportunidade de expressar e reconhecer o papel que representa neste cada um destes.

Nesta etapa de desenvolvimento do processo da cidadania, começa a dialogar sobre a necessidade de dar uma organização no Processo Comunitário e as distintas alternativas que apresentam. Se forma um grupo de trabalho que apresenta uma primeira proposta (maio de 2006) que serve de base ao diálogo. Há unanimidade em considerar o importante e positivo deste espaço de encontro que constitui o gérmen de uma futura organização social da população no Processo Comunitário e na necessidade de seguir aprofundando na proposta realizada.

\section{Momento atual. Os Novos Objetivos (2007-2008) 6.1. Os Recursos Técnicos}

"O grupo de coordenação dos técnicos, já consolidado constitui um importante capital humano e técnico absolutamente necessário para abordar temas que nenhum recurso por si só poderia fazer, como o início da análise da realidade da Margem Direita do Guadiana, análise que desembocará no Diagnóstico Comunitário".

Começa o trabalho para realizar a Monografia Comunitária no ano de 2006, recopilando e organizando o conjunto de dados, estudos e conhecimentos setoriais e/ ou parciais que existem sobre a zona e que, como se sabe, estão dispersos. Este trabalho permitirá a construção de um primeiro diagnóstico objetivo do território, tanto desde uma perspectiva global, como setorial e por faixas etárias da população. Para isto continua-se capacitando, também nesta etapa, mediante a formação e desenvolvimento da: "Monografia Comunitária e a Audição" (parte 1), em maio 2006, (parte 2), em janeiro de 2007.

Os técnicos se organizam em seis comissões: uma primeira comissão que se encarrega dos dados estruturais (população, geografia, história do bairro, das associações); e também uma comissão para cada um dos setores de educação, saúde, social e assistencial, ocupacional, e esportes; lazer, cultura e tempo livre.

É possível abordar nesta etapa do processo o trabalho de coletar os dados, e o compromisso do Comitê Técnico, a financiamento obtido pelo Centro de Saúde "El Progresso" com o projeto de investigação participativa para a realização do diagnóstico comunitário da Margem Direita do Guadiana em Badajoz, apresentado a Secretaria de saúde 
(D.O.E. 20 de dezembro de 2005) que permite contar com um estagiário cedido por esta, para a coordenação das comissões de trabalho. Também a Equipe Comunitária se complementa com o trabalho de outra pessoa estagiária proveniente do Gabinete de Estudos e Análise.

O trabalho de coleta dos dados, elaboração dos informes de cada comissão e realização de um documento "Síntese" para a difusão destes primeiros resultados, se desenvolve durante o ano de 2006, e se apresenta no II Encontro do Proceso Comunitário da Margem Direita do Guadiana em março de 2007.

Foi criado blog do mesmo, (wnw.procesocomunitariomdg.blogspot.com) e a Guia de recursos para a infância e a adolescência, se supõe um momento importante com um nível de participação muito alto por parte dos três protagonistas (150 assistentes) e uma avaliação muito positiva.

O alto grau de colaboração e coordenação estabelecido entre os técnicos fica patente pela apresentação da Monografia Comunitária, pelo compromisso estabelecido para levar adiante a audição-técnica de investigação participativa que consiste na livre escuta dos protagonistas da comunidade mediante colóquios (elevado número de pessoas, massiva assistência aos cursos de formação, etc.) durante os meses de março e abril de 2007, seguindo a proposta do assessor.

Realizou-se 92 colóquios individuais a testemunhas privilegiadas formais (representantes de associações, recursos técnicos, etc.), não formais, 17 colóquios grupais. Definem-se como necessidades para a continuação do trabalho complementar esta coleta de informação qualitativa com as aportações de testemunhas externas da comunidade, a elaboração de histórias de vida, assim como o tratamento de toda a informação obtida para construir um diagnóstico compartido e abordar a planificação comunitária.

\subsection{As Instituições}

Desde os primeiros passos do processo se informou a todas e a cada umas das administrações-instituições do que se ia realizando no PCMDG.

Em junho de 2006 reuniu-se pela primeira vez a
Comissão Institucional de Seguimento do Processo Comunitário que estavam convidadas todas as instituições. Em dezembro de 2006 se retornou a reunir e aprovou o Regulamento de Funcionamento da Comissão.

Apesar de se ter planejado reunir-se semestralmente, em 2007, não houve nenhum reunião por razões distintas. Em junho de 2007 acabavam de celebrar as eleições locais, com as mudanças que isto comporta nas diferentes secretarias municipais e estaduais. Posteriormente, diferentes questões deixaram a Equipe Comunitária que dinamiza o PCMDG e realiza o trabalho de secretário/a da Comissão quase sem componentes, o que impossibilitava a preparação e seguimento das reuniões.

Em abril de 2008 se reúne a Comissão Institucional depois de um ano e meio parada, foi uma reunião principalmente informativa sobre a situação do PCMDG e os seguintes passos: finalização e apresentação do diagnóstico, divulgação e próxima etapa do PCMDG. Na reunião se debateu se era necessário um reconhecimento formal do espaço de coordenação dos recursos técnicos que participam no PCMDG, isto é, do Comitê Técnico Assessor. A próxima reunião será em outubro de 2008, e previsivelmente se firmará esse reconhecimento formal do espaço de coordenação de recursos.

\subsection{Cidadania}

Após ampla divulgação (desde novembro de 2004) e haver trabalhado com todas as associações e cidadãos da zona a forma de organizar-se (desde finais de 2005), em outubro de 2007 se constitui o Núcleo da Cidadania (espaço operativo e organizativo) com todo tipo de coletivos e pessoas a título individual. É importante salientar que este Núcleo é aberto, que as decisões se tomam por consenso e que há representantes de todo os tipos de associações e bairros da Margem Direita, além de pessoas a título individual.

O Núcleo conta com uma pessoa que serve de ligação com a equipe comunitária, nomeada por unanimidade. As decisões importantes se tomam sempre no Grupo Comunitário (formado por todas as associações e pessoas que a título individual querem participar) por consenso. Sen- 
do a informação um dos elementos essenciais para a participação, tudo que é discutido no Núcleo e nas assembléias do Grupo Comunitário é enviado a todo mundo (quase 100 pessoas, entre associações e pessoas a título individual que querem participar).

É importante salientar, que a Cidadania já está organizada para relacionar-se com o resto dos protagonistas da Comunidade e participa de forma ativa na tomada de decisões do Processo Comunitário: propõe-se atividades e escolhe-se as pessoas para as histórias de vida, participaram no II Encontro Comunitário de março de 2007, e se colaborou com as audições para o Diagnóstico Comunitário, participando ativamente no Comitê Organizador das I Jornadas Comunitárias da Margem Direita do Guadiana de junho de 2008, levando o peso da organização dos atos lúdicos de divulgação do PCMD.

\subsection{Breve cronologia das relações entre os três prota- gonistas}

Os três protagonistas da Comunidade não somente estão organizados e aportando o PCMDG, como também as relações entre eles estão crescendo. Em síntese, o desenvolvimento das mesmas foi:

Em 2004 apenas havia relação entre os diferentes protagonistas, cada um começava a conhecer e organizar.

Em 2005 a situação era similar ainda que:

No mês de março se desenvolveu o Primeiro Encontro de Associações e Cidadãos da Margem Direita do Guadiana.

Em novembro de 2005 se celebrou o I Encontro Comunitário da Margem Direita do Guadiana na Paróquia de São Fernando e Santa Isabel: ali se encontraram instituições (Prefeitura, Estado), recursos técnicos e as diferentes associações e cidadãos.

Em 2006 a Comissão Institucional se reúne (em junho e em dezembro) confeccionando um Regulamento de Funcionamento. Ao mesmo tempo, a cidadania analisa como organizar-se e os técnicos trabalham coordenadamente (muitos deles na Monografia Comunitária - estudo objetivo-quantitativo da MDG), mas não há nenhum encontro entre os mesmos.

Em 2007 se celebra em março o II Encontro Comunitário no Colégio Público Juan Vázquez onde:

A cidadania nomeia um grupo de pessoas para que falem em seu nome;

Os técnicos apresentam diferentes produtos: Monografia Comunitária, a Guia de Recursos da Infância e a Adolescência e o blog do PCMDG;

Os responsáveis de instituições-administrações presentes no encontro tomam a palavra para animar a seguir trabalhando.

Em outubro deste mesmo ano se constitui o Núcleo da cidadania com suas normas de funcionamento. Ambos núcleos (cidadãos e técnicos) intercambiam informações, facilitando assim a relação e o apoio mútuo.

Em junho de 2008 se apresentou o Diagnóstico Comunitário no III Encontro Comunitário. Coincidindo com o III Encontro Comunitário dos três protagonistas do PCMDG se celebraram as I Jornadas Comunitárias da MDG de Badajoz nos días 12 e 13 de junho de 2008. Para preparar estas Jornadas, técnicos e Cidadãos se organizaram e coordenaram-se em um Comitê, com reuniões quinzenais repartindo-se as tarefas desde abril até a avaliação posterior a celebração das Jornadas, sempre com a dinamização, informação, assessoramento, etc.

\section{A Equipe Comunitária (EC)}

Desde novembro de 2003 até setembro de 2006 a equipe esteve composta por Carmen Mata (Assistente Social liberada a tempo completo pela Gerência da Área de Saúde) e com o apoio de um animador sócio-cultural para a coordenação da Monografia (desde dezembro de 2005 graças a um projeto de investigação da Secretaria de saúde e dependência).

Desde setembro de 2006 a outubro de 2007 se incorporam a EC - em tempo parcial - uma educadora (Instituto Municipal de Serviços Sociais da Prefeitura de Badajoz (IMSS), 3 horas semanais; uma assistente social (Secretaria de Bem-estar Social, dois dias por semana) e uma enfermeira (graças a um projeto de investigação da Secretaria de Saú- 
de e Dependência), assim como o trabalho voluntário de outros dois profissionais em momentos concretos do processo.

Desde outubro de 2007 até final de fevereiro de 2008 houve uma situação de precariedade: por diferentes motivos a Equipe Comunitária ficou reduzida à educadora, à enfermeira e ao animador sócio-cultural, ainda que se pôde contar com o trabalho voluntário de um psicólogo (formado na Metodologia de Intervenção Comunitária pelo Instituto Marco Marchioni (IMM)). Por outro lado, em $1^{\circ}$ de março de 2008 teve que abandonar o local do Centro de Saúde El Progresso (cedido pela gerência de Área de Saúde de Badajoz). A situação era insustentável.

Desde finais de fevereiro de 2008 se conta com uma renovada Equipe Comunitária, formada por cinco profissionais: a educadora del IMSS (3 horas por semana); um animador sócio-cultural de dedicação completa (pertencente ao IMM); um psicólogo (meia jornada com um projeto de investigação da Secretaria de Saúde e Dependência assegurado para todo o ano de 2008); se incorporou uma psicopedagoga de dedicação completa (Secretaria de Educação) e uma assistente social (2 dias da semana, Secretaria de Igualdade e Emprego). Fica para o futuro um trabalho de organização, divisão de tarefas e funções, assim como formação em processos comunitários das pessoas recentemente incorporadas.

Desde março de 2008 se conta com um novo local mais amplo situado no Instituto de Ensino Secundário São José, a cargo da Secretaria de Educação, a reforma, manutenção e melhoria.

Detectou-se a necessidade de contar com alguma pessoa com capacidade técnica e tempo para realizar as tarefas informativas (cartazes, panfletos, blog, vídeos, fotos, etc.), ou também, com a colaboração voluntária e permanente de algum recurso da zona.

\section{Diagnóstico comunitário}

Para desenvolver um processo comunitário é necessária a coordenação dos recursos existentes em uma comunidade. Para que esta coordenação evolua para uma in- tervenção conjunta, é necessária a realização de um Diagnóstico Comunitário que possibilite uma visão compartida, global e integral da comunidade.

O Diagnóstico Comunitário da Margem Direita do Guadiana se baseia na análise e interpretação de dados quantitativos já recolhidos da Monografia Comunitária e de dados qualitativos, seguindo a metodologia de Marco Marchioni, em que a comunidade é objeto e sujeito da investigação, facilitando a participação dos três protagonistas tanto no diagnóstico como na intervenção propriamente dita.

No ano de 2006, com o assessoramento e a formação adequada, se realizou a Monografia Comunitária: uma recopilação e organização dos dados e conhecimentos objetivos da zona. Em março de 2007 se publicou e se difundiu a Síntese da Monografia Comunitária, apresentada no "II Encontro Comunitário".

Em março-abril de 2007 começou a coleta de dados qualitativos para a realização do diagnóstico. Para isto, se realizaram audições, entrevistas a pessoas representativas da Margem Direita do Guadiana por sua vida e/ou trabalho na zona. Com este método de escuta da comunidade se realizaram 92 audições individuais e 17 grupais, com um total de 217 pessoas.

A análise e interpretação dos dados se realizou desde janeiro de 2008 por duas professoras do Departamento de Direção de Empresa e Sociologia da Universidade de Extremadura (UEX) e um licenciado em psicologia, membro da Equipe Comunitária e bolsista pela Secretaria de Saúde e Dependência para a realização do projeto de Investigação: Investigação participativa para a realização do Diagnóstico Comunitário da Margem Direita do Guadiana. Se desenvolveu uma categorização do conteúdo das audições, uma análise de conteúdo com um programa informático criado por "O Pátio" (Programa da Secretaria de Bem-estar, Juventude e Vivenda do Governo de Canárias) e cedido gratuitamente.

Estes três recursos técnicos junto a outra professora do mesmo Departamento, o médico que coordenou a realização do Diagnóstico Participado de Saúde da Zona 
de Saúde El Progresso, na Margem Direita, e o Assessor constituiram o Comitê de Redação do Diagnóstico Comunitário, encarregados da elaboração do mesmo, com a colaboração da Equipe Comunitária. O Comitê de Redação do Diagnóstico elaborou o Diagnóstico Comunitário dependente de aportações pontuais de um Comitê de Revisão formado por técnicos pertencentes ao Comitê Técnico da MDG e que será publicado ao final de 2008.

O Diagnóstico incluirá histórias de vida de pessoas com uma trajetória vital importante eleitas pelos cidadãos que participam do Processo, a visão que as crianças tem da comunidade expressada com desenhos, a imagem que a cidade de Badajoz tem da Margem Direita e a aportação do assessor.

Para pesquisar as histórias de vida se realizou uma oficina ministrada por um professor da Escola de Enfermagem do Serviço Extremenho de saúde (SES) e licenciado em antropología, e um psicólogo, membro da Equipe Comunitária. Quatorze técnicos participaram do mesmo e oito se encarregaram de realizar as histórias.

Por outro, era necessária a aportação da infância, e para isto, se realizou um concurso de desenho. O concurso foi dia 20 de novembro de 2007, "Dia Internacional da Infância", no distintos centros de educação primária da zona. De maneira anônima cada criança pôde desenhar o que mais gosta de seu bairro e por outro lado o que menos gosta. Estes poderão publicar ou expor dentro das atividades do Processo Comunitário e se utilizarão para ilustrar o Diagnóstico Comunitário, mais um informe realizado por uma equipe de profissionais da zona: um psicopedagogo das Equipes de Orientação Educativa e Psicopedagógica de Badajoz e um psicólogo do Instituto Marco Marchioni - IMSS.

O Diagnóstico também incluirá a visão que a cidade de Badajoz têm da Margem Direita, já que esta é uma zona, região muito importante da cidade. Esta aportação foi através de audições a personalidades da cidade (representantes municipais de partidos políticos e sindicatos, do mundo econômico, organizações empresariais, etc. As entrevistas foram realizadas pelo assessor.
Como resumo deste apartado podemos dizer que o Diagnóstico Comunitário inclui uma análise convergente da informação objetiva, recolhida e organizada em forma de Monografia Comunitária, e da informação subjetiva recolhida mediante a técnica de investigação participativa da Audição. Além da visão da MDG na cidade mediante a audição de testemunhas externas, a visão das crianças da comunidade através de desenhos, e oito histórias de vida. Baseado neste documento publicou-se em junho a Síntese do Diagnóstico Comunitário.

\section{Conclusão}

Esta primeira etapa do Processo Comunitário desenvolveu o Diagnóstico com todas as pessoas envolvidas e divulgou os resultados a toda a comunidade. A próxima etapa é a formação dos técnicos e líderes para se fazer a intervenção Comunitária.

Seguindo o esquema da análise DAFO, se pode dizer que a Margem Direita do Guadiana (MDG) tem umas debilidades e umas fortalezas (análise interno), e que se aproximam uma série de ameaças e de oportunidades (análise externo).

Em relação á análise interno, a principal debilidade são os grandes desequilíbrios existentes na MDG: nos referimos a diferenças sócio-culturais, econômicas, infraestruturais e a dimensão de suas necessidades, demandas e inquietudes. Qualquer consideração sobre a MDG tem que se considerar esta acentuada heterogeneidade, igual que qualquer intervenção na zona terá que considerar a redução destas diferenças. Por outro lado, as fortalezas são muitas. Destaca-se o forte tecido associativo da zona como instrumento efetivo para canalizar seu desenvolvimento, e a solidariedade e participação cidadã de uma comunidade que quer e pode ser protagonista de seu desenvolvimento. Também é importante a existência do PCMDG, que conta com a implicação das Instituições, dos Recursos Técnicos, e da Cidadania, sem dúvida alguma, um ponto de chegada importante. Portanto, é uma grande fortaleza, e também um ponto de chegada, a existência de uma visão compartilhada da realidade pelos três protagonistas graças ao 
Diagnóstico Comunitário.

Em uma análise externa, a principal ameaça são as mudanças que sempre sucedem: econômicos, políticos, sociais que podem fazer que aumente a dicotomização social existente e que os desequilíbrios sejam irrecuperáveis. Com o PCMDG se gerou uma série de expectativas, que no caso de não se cumprir poderia provocar uma grade desilusão e sentimentos de fracasso aos implicados neste PCMDG. Enquanto as oportunidades são muitas e devem saber aproveitar. $\mathrm{O}$ desenvolvimento econômico da zona vem marcado pela construção da plataforma logística que se converterá em um foco de crescimento para Badajoz. A Margem Direita, onde se localiza, pode ser favorecida pelo efeito multiplicador de um desenvolvimento econômico focal, fundamentalmente enquanto ao desenvolvimento dos serviços, infra-estruturas níveis de formação e emprego na zona. A grande oportunidade é o Plano Comunitário que tem como objetivo ao melhorar a realidade da MDG, mediante intervenções concretas com a participação dos três protagonistas que serão quem decide que mudar e como fazer.

Para se conseguir uma participação comunitária e gestão participativa efetiva há que ter persistência e aproveitar as oportunidades. O tecido associativo do PCMDG e o Diagnóstico, serve para unir em um objetivo comum a dicotomização já existente, contribuindo para que as mudanças sejam positivas, e que as ameaças se transformem em oportunidades.

\section{Referências}

1. Marchioni M. Comunidad, participación y desarrollo (2001). Teoría y metodología de la intervención comunitaria. Ed. Popular. Madrid.

2. Marco Marchioni. Salud y Comunidad (2002). Ponencia IV Encuentros del PACAP. Madrid.

3. Grupo PACAP Extremadura (2004). Documento: La Promoción de la salud a través de las actividades comunitarias en los Centros de Salud. Badajoz.

4. PACAP semfyc (2004). I Recomendaciones PACAP. ¿Cómo iniciar un proceso de intervención y participación comunitaria desde un centro de salud? Madrid.

5. Equipo de Atención Primaria. Centro de Salud El Progreso (Badajoz) (2006). Análisis de la Situación de Salud de la Zona de Salud El Progreso. Badajoz. Diciembre.

6. Ministerio de Sanidad y Consumo (2006). Proyecto AP 21: Estrategia para la Atención Primaria del siglo XXI. Madrid.

7. Os centros de saúde e os processos comunitários'. Ignácio Maynar, Dolores Fernández, Carmen Mata. I Simposio IMM Comunidad Participación y Desarrollo 1965-2005. Avilés, 29 y 30 de abril de 2005.

\section{Endereço para correspondência:}

Alameda dos Manacás, 137

Bosque da Ribeira - Nova Lima - MG

CEP: 34000-000

Tels: (031)35811240

\section{Endereço eletrônico:}

caroldoliveira@yahoo.com.br 